\title{
Assessing the risk of climate change to aquaculture: a case study from south-east Australia
}

\section{Zoë A. Doubleday ${ }^{1,8}$, Steven M. Clarke ${ }^{2, *}$, Xiaoxu Li $^{2}$, Gretta T. Pecl ${ }^{1}$, Tim M. Ward ${ }^{2}$, Stephen Battaglene ${ }^{1}$, Stewart Frusher ${ }^{1}$, Philip J. Gibbs ${ }^{3}$, Alistair J. Hobday ${ }^{4}$, Neil Hutchinson ${ }^{5,9}$, Sarah M. Jennings ${ }^{6}$, Richard Stoklosa ${ }^{7}$}

\author{
${ }^{1}$ Fisheries, Aquaculture \& Coasts, Institute for Marine \& Antarctic Studies, University of Tasmania, Hobart, Tasmania 7053, \\ Australia \\ ${ }^{2}$ Aquatic Sciences, South Australian Research \& Development Institute and Marine Innovation South Australia, \\ West Beach, South Australia 5024, Australia \\ ${ }^{3}$ Department of Primary Industries NSW, Cronulla Fisheries Research Centre, Cronulla, New South Wales 2230, Australia \\ ${ }^{4}$ Climate Adaptation Flagship, CSIRO Marine \& Atmospheric Research, Hobart, Tasmania 7000, Australia \\ ${ }^{5}$ Fisheries Research Branch, Department of Primary Industries, DPI Queenscliff Centre, Queenscliff, Victoria 3225, Australia \\ ${ }^{6}$ School of Economics \& Finance, University of Tasmania, Hobart, Tasmania 7001, Australia \\ ${ }^{7}$ E-Systems Pty Limited, Hobart, Tasmania 7000, Australia
}

${ }^{8}$ Present address: Southern Seas Ecology Laboratories, School of Earth \& Environmental Sciences, University of Adelaide, South Australia 5005, Australia

${ }^{9}$ Present address: JCU Singapore, TropWATER - Centre for Tropical Water and Aquatic Ecosystem Research, James Cook University, 600 Upper Thomson Road, Singapore 574421

\begin{abstract}
A qualitative screening-level risk assessment was developed to evaluate relative levels of risk from climate change to aquaculture industries. The assessment was applied to 7 major industries in the temperate south-east region of Australia and involved a simple, transparent and repeatable methodology that was appropriate for a range of different aquaculture systems and taxa. Two key stages were involved: the development of comprehensive expertise-based literature reviews or 'species profiles' and a scoring assessment, with the latter providing a defined framework within which industries could be ranked (from high to low risk). In addition to informing the second stage of the risk assessment process, the species' profiles also highlighted important climate change drivers and key information uncertainties and knowledge gaps. There was good resolution among the scoring assessments, with only 2 industries receiving the same risk score. The results indicated that oysters farmed from wild spat (Sydney rock oysters Saccostrea glomerata) were at most risk to climate change, with warm temperate hatchery-based finfish species (yellowtail kingfish Seriola lalandi) being the least at risk. This study provides critical guidance for scientists, resource managers and stakeholders for future research, both in addressing key knowledge gaps and focussing the development of more detailed risk analyses for high risk aquaculture industries in south-east Australia.
\end{abstract}

KEY WORDS: Risk assessment $\cdot$ Climate change $\cdot$ Aquaculture $\cdot$ Australia Resale or republication not permitted without written consent of the publisher

\section{INTRODUCTION}

Increasing concentrations of greenhouse gases in the atmosphere due to human activities are driving changes in global climate at a magnitude and rate greater than at any other time in human civilisation (IPCC 2007, Solomon et al. 2009). In marine and estuarine environments climate change can lead to 
changes in ocean temperature and $\mathrm{pH}$, sea level, wind and current patterns, salinity, and the frequency, duration and intensity of extreme climatic events, which are all likely to impact marine biodiversity and resources (Brander 2007, Poloczanska et al. 2007, Brierley \& Kingsford 2009), and, ultimately, the communities and industries that depend upon them (Hobday et al. 2008, Allison et al. 2009). Aquaculture is one of the fastest growing primary production sectors in the world, providing significant social and economic benefits globally and accounting for approximately $45 \%$ of aquatic animal food produced for human consumption (De Silva \& Soto 2009, Bostock et al. 2010). As the human population grows aquaculture production is expected to increase further to meet escalating demands for high-quality protein and to ensure food security (De Silva \& Soto 2009, Bostock et al. 2010, Garcia \& Rosenberg 2010, Godfray et al. 2010). Climate change is predicted to critically impact many aquaculture systems around the world through its effects on species' physiology (e.g. changes in growth rate, reproductive output and disease susceptibility) and farming practises (e.g. changes to farm locations, infrastructure and husbandry) (Handisyde et al. 2006, Brander 2007, Hobday et al. 2008, Cochrane et al. 2009, De Silva 2012). It is therefore imperative that vulnerable aquaculture industries are identified, thereby allowing researchers, managers and stakeholders to optimally allocate financial and human resources to address the key challenges and develop adaptation strategies.

Ecological risk assessments can be used to estimate the relative probability of adverse outcomes occurring and can thus help elucidate and prioritise various risks or sources of risks; for example, from the effects of fishing (Fletcher 2005, Arrizabalaga et al. 2011, Hobday et al. 2011), coastal development (Samhouri \& Levin 2012), conservation planning (Gallagher et al. 2012), or climate change (Chin et al. 2010). A typical assessment of risk consists of the combination of the internationally recognised terms 'consequence' (i.e. of an event) and 'likelihood' (i.e. of the event's occurrence) (see the Australian/New Zealand Standard for risk management [reproduced from the International Standard], AS/NZS 2009). In our case study, these 2 dimensions translate to the level of impact if anticipated climate change occurs, based on prior knowledge and level of uncertainty, and the adaptive capacity of different aquaculture industries to climate change, based on species biology and farming processes. There are many ways to assess risk, and a hierarchical approach that encompasses various risk analysis stages is a useful way to focus resources and research effort (Hobday et al. 2011). In the approach developed by Hobday et al. (2011), 'units' (such as aquaculture industries) that are identified as being at low risk in the first stage (e.g. a broad qualitative scoping study) do not require more complex and labour-intensive analysis (e.g. a fullyquantitative modelling-based study). Financial allocations to natural resource management are invariably limited, and investment in climate change research, planning and adaptation is no exception. Therefore, a first-pass screening-level assessment of the risk of climate change to aquaculture represents an initial step towards focussing more detailed analyses on industries identified as being at high risk.

The south-east region of Australia has been the focal region of this study for development of risk assessment methods with global applicability, for identifying key climate change issues to the aquaculture industry and for establishing a prioritised framework for future research. Due to the strengthening of the East Australian Current (Ridgway 2007, Hill et al. 2008) the waters off south-eastern Australia have been identified as a climate change 'hotspot', warming at 3 to 4 times the global average (Ridgway 2007, A. J. Hobday \& G. T. Pecl unpubl. data). It is also projected that the region will experience further increases in temperature, sea level and upwelling (Hobday \& Lough 2011), and, particularly within estuarine waters, salinity increases due to reduced rainfall and increased evaporation (Gillanders et al. 2011). The south-east is also the most important region for aquaculture in Australia, contributing 74 and $30 \%$ to the total value of aquaculture (AUS\$870 million) and seafood (AUS $\$ 2.2$ billion) production, respectively, in 2009/2010 (ABARE 2011). Furthermore, key aquaculture industries within the region are based on both finfish and shellfish and involve a variety of farming methods, which span onshore (e.g. tank-based), intertidal and offshore environments.

In this study, we develop a novel qualitative screening-level risk assessment to analyse relative levels of risk to key aquaculture industries from climate change impacts in south-east Australia. An over-arching aim was to also develop a repeatable and comprehensive methodology that would have global application to a wide range of locations and aquaculture systems, and, on a more local level, provide scientific advice to resource managers and stakeholders regarding the likely impacts of climate change to aquaculture in the region and to identify research required to develop and refine projections of climate change. 


\section{METHODS}

A 2-stage process was designed to test the relative risk of key aquaculture industries to climate change in the south-east Australian region. The region comprises 4 state jurisdictions; New South Wales (NSW), South Australia (SA), Tasmania and Victoria (Fig. 1). Six species and 1 species group (abalone) (referred to as just 'species' hereafter) were selected for inclusion in the risk assessment based on level of economic importance within the region (Table 1). Two broad taxonomic groups, namely finfish and shellfish species, and an array of farming methods were represented among the 7 selected species. If a species was farmed using $>1$ farming system, a risk assessment was conducted for each method. In total, 11 individual risk assessments were completed: abalone Haliotis spp. (sea-based farming), abalone (land-based farming), Atlantic salmon Salmo salar, blue mussel Mytilus galloprovincialis (hatchery-produced spat), blue mussel (wild-sourced spat), Pacific oyster Crassostrea gigas, southern bluefin tuna Thunnus maccoyii (hatchery-produced juveniles), southern bluefin tuna (wild-sourced juveniles), Sydney rock oyster Saccostrea glomerata (hatchery-produced spat), Sydney rock oyster (wild-sourced spat), and yellowtail kingfish Seriola lalandi.

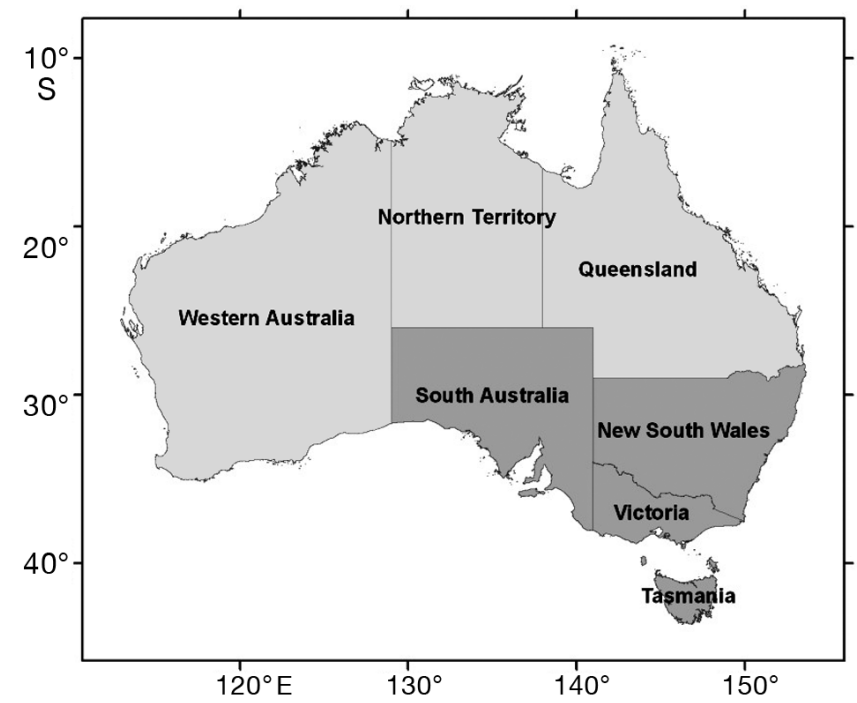

Fig. 1. The south-east region of Australia (highlighted in dark grey)

\section{Stage 1: descriptive syntheses (species profiles)}

The first component of the risk assessment involved the development of comprehensive species profiles for each of the 7 species detailed in Table 1 . These profiles were based on a consistent template and collated and synthesised existing data, pub-

Table 1. Species selected for risk assessment analysis. A: adults; B: broodstock; L: larvae; S: spat; J: juveniles. Monetary values from the 2009/2010 financial year (ABARE 2011, Econsearch 2011); farming regions include commercial-level operations in the south-east region of Australia

\begin{tabular}{|c|c|c|c|c|}
\hline Common name & Scientific name & $\begin{array}{l}\text { Value (AUS\$, } \\
\text { in millions) }\end{array}$ & Farming methods & Farming regions \\
\hline $\begin{array}{l}\text { Abalone } \\
\text { - Blacklip } \\
\text { - Greenlip } \\
\text { - Tiger }\end{array}$ & $\begin{array}{l}\text { Haliotis spp. } \\
\text { H. rubra } \\
\text { H. laevigata } \\
\text { A hybrid of the } 2 \text { species }\end{array}$ & 15 & $\begin{array}{l}\text { Hatchery }(\mathrm{B}, \mathrm{L}, \mathrm{S}) \\
\text { land-based tanks and raceways } \\
\text { or sea cages }(\mathrm{A})\end{array}$ & South Australia, Victoria, Tasmania \\
\hline Atlantic salmon & Salmo salar & 362 & $\begin{array}{l}\text { Hatchery (B, fry, parr); } \\
\text { brackish and marine sea cages } \\
\text { (smolts, A) }\end{array}$ & Tasmania \\
\hline Blue mussel & Mytilus galloprovincialis & 8 & $\begin{array}{l}\text { Hatchery }(\mathrm{B}, \mathrm{L}, \mathrm{S}) \text { or collection } \\
\text { from wild using longlines }(\mathrm{S}) ; \\
\text { longlines }(\mathrm{A})\end{array}$ & South Australia, Victoria, Tasmania \\
\hline Pacific oyster & Crassostrea gigas & 56 & $\begin{array}{l}\text { Hatchery }(\mathrm{B}, \mathrm{L}, \mathrm{S}) \text {; intertidal } \\
\text { baskets }(\mathrm{A})\end{array}$ & $\begin{array}{l}\text { South Australia, New South Wales, } \\
\text { Tasmania }\end{array}$ \\
\hline $\begin{array}{l}\text { Southern bluefin } \\
\text { tuna }\end{array}$ & Thunnus maccoyii & 102 & $\begin{array}{l}\text { Hatchery (L) (production limited, } \\
\text { currently in research and develop- } \\
\text { ment stage); collection from wild, } \\
\text { sea-ranching (J, A) }\end{array}$ & South Australia \\
\hline Sydney rock oyster & Saccostrea glomerata & 43 & $\begin{array}{l}\text { Hatchery }(\mathrm{B}, \mathrm{L}, \mathrm{S}) \text { or collection from } \\
\text { wild using stick culture }(\mathrm{S}) \text {; stick } \\
\text { or tray culture }(\mathrm{A})\end{array}$ & New South Wales \\
\hline Yellowtail kingfish & Seriola lalandi & 27 & $\begin{array}{l}\text { Hatchery }(B, L, J) ; \\
\text { marine sea cages }(A)\end{array}$ & South Australia \\
\hline
\end{tabular}


lished and grey literature, and expert opinion on the industry, production, the species' life history, farming process, current and potential climate change impacts, and critical data gaps. The profiles were typically 3000 to 5000 words in length (see Pecl et al. 2011 to view the profiles) and were produced by 16 expert authors and reviewers representing both science and industry and all 4 state jurisdictions (for more information see 'Acknowledgements' and author affiliations). The key results from the individual species profiles were summarised and tabulated and subsequently used to inform the second stage of the risk assessment. This step is commonly known as the scoping stage in many risk assessment methods (AS/NZS 2009, e.g. Scandol et al. 2009, Hobday et al. 2011)

\section{Stage 2: scoring assessment}

The second stage of the assessment involved ranking each of the 11 species/farming method combinations (hereafter referred to as 'industries') from high to low risk using a defined, qualitative, scoring framework. The framework was developed by a panel of 12 scientists during two $1 \mathrm{~d}$ workshops and ongoing post-workshop consultation, in conjunction with the extensive literature reviews derived from the species profiles (see Pecl et al. 2011 for the list of literature reviewed). Development was led by 2 panel members, who had extensive expertise on aquaculture research and the industries in the region, and facilitated by the broader group, who had a range of experience in risk analysis and climate change science.

This framework was based around 9 key attributes designed to assess the risk of all aquaculture species and relevant farming processes to climate change (Table 2). Attributes encompassed all basic farming and life-history stages, including broodstock conditioning, spawning, larval rearing, juvenile rearing and growout, with several encompassing the level of exposure to natural environmental conditions. Two types of scores were then assigned to each of the 9 attributes: a sensitivity score and an impact score. The former involved 3 scoring categories, low (1), medium (2) and high (3), in relation to level of sensitivity, defined here as an inability to respond to climate change (see Table 2 for category definitions). The impact score was based on the level of known or predicted impacts of climate change, and was defined as follows: mild negative impact, positive impact, or no impact anticipated $(0)$; moderate negative impact or level of impact unknown (1); and strong negative impact (2) (see Table 3 and Appen- dix 1 for worked examples). The scores were initially allocated by the 2 leading members of the scientific panel, based on the information collated from Stage 1, and, again, finalised through general consensus from the broader group.

The next stage of the scoring assessment involved calculating a risk score for each attribute by multiplying the sensitivity score by the impact score. The scores were multiplied to approximate a 'weighting factor' and thus allow levels of impact and uncertainty to be incorporated. Subsequently, risk scores from each of the 9 attributes were summed to obtain a total risk score, with a potential range of 0 to 54, for each of the 11 industries. The industry with the highest score was ranked as being the most at risk to climate change. Level of risk for each industry in this study was defined by dividing the observed score range, 9 to 34, into approximate thirds as follows - low: 9 to 17, medium: 18 to 25 and high: 26 to 34 . In addition, a total attribute risk score was determined for each of the 9 attributes (i.e. farming process or stage) by summing the risk scores across all 11 industries.

\section{RESULTS}

\section{Species profiles}

There were few known climate change impacts identified in the species profiles, and those that were generally regarded to be of low to medium certainty. Only a small number of reported impacts were identified as having direct or highly certain linkages to climate change (e.g. for yellowtail kingfish Seriola lalandi 'flukes [parasites] present greater problems in increased water temperature') (Table 4). While a range of predicted impacts were described for all species, most were described with only low to medium certainty. It should be emphasised that such low certainty is a reflection of limited scientific information and the relative infancy of climate-related aquaculture research.

In regards to both current and predicted impacts (Table 4), temperature was the most frequently cited climate change driver, being linked to stress, immune-suppression, increases in pests and diseases, and to changes in farm husbandry practices (e.g. increased cleaning of infrastructure and reduced fallowing periods). Ocean acidification was highlighted as another key driver and was predicted to impact the growth, development and survival of the 4 shellfish species, with low to medium certainty, as the time scale for this impact was perceived as 


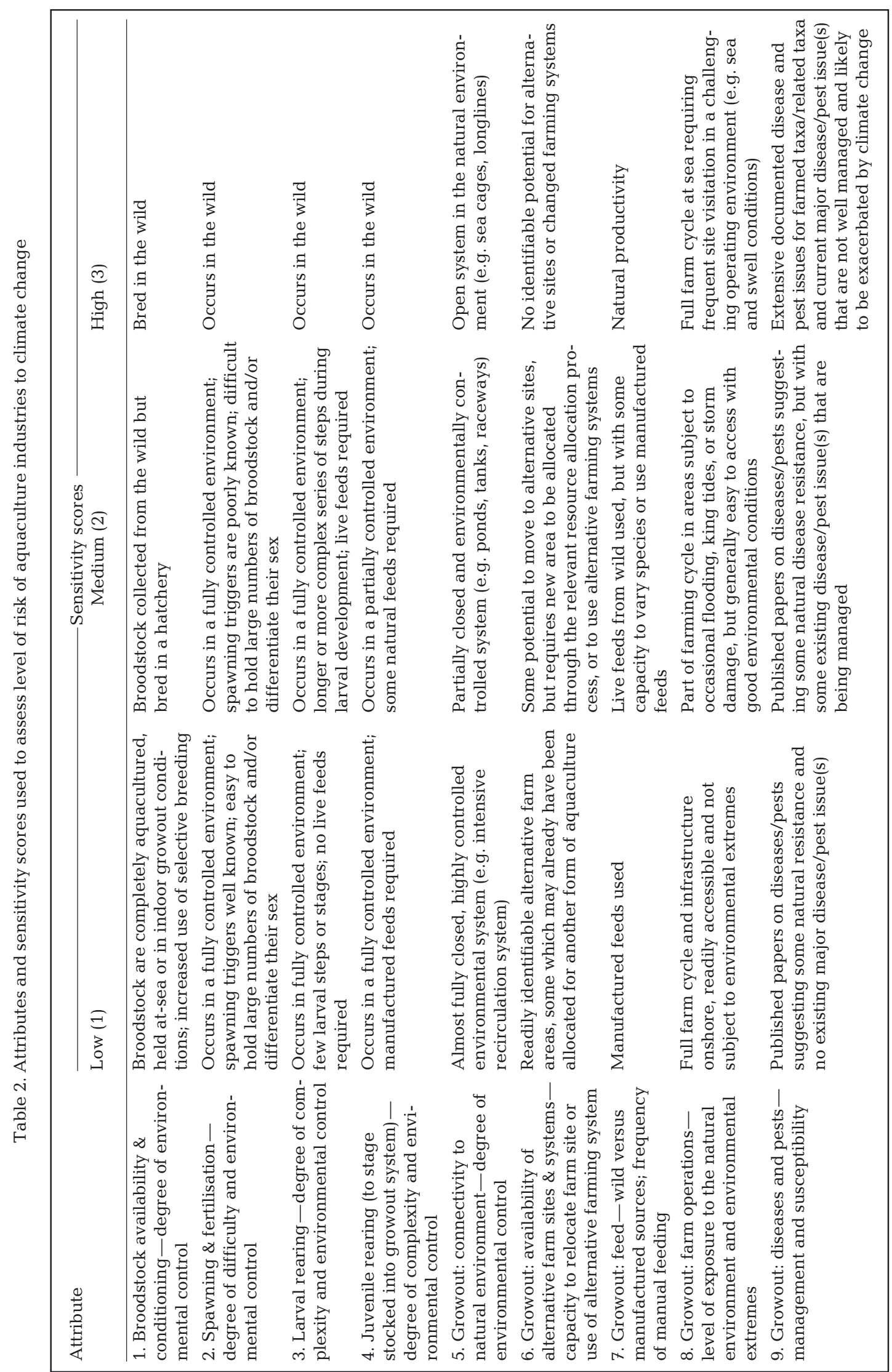


Table 3. Example scoring for land-based abalone risk assessment with explanation for each score provided. The risk score is the sensitivity score (see Table 2) multiplied by the impact score (mild negative impact, positive impact, or no impact anticipated [0]; moderate negative impact or level of impact unknown [1] and strong negative impact [2]); the total risk score is the sum of risk scores. Attributes are detailed in Table 2. Similar scoring tables were developed for each species under assessment (see Appendix 1)

\begin{tabular}{|c|c|c|c|c|c|}
\hline \multirow{2}{*}{$\begin{array}{l}\text { Attri- } \\
\text { bute }\end{array}$} & \multirow{2}{*}{\multicolumn{2}{|c|}{$\begin{array}{lc} & \text { Sensitivity score } \\
\text { Score } & \text { Explanation }\end{array}$}} & \multicolumn{2}{|r|}{ Impact score } & \multirow{2}{*}{$\begin{array}{l}\text { Risk } \\
\text { score }\end{array}$} \\
\hline & & & Score & Explanation & \\
\hline 1 & 2 & $\begin{array}{l}\text { Broodstock collected from the wild, but increas- } \\
\text { ingly being held in the aquaculture system }\end{array}$ & 1 & $\begin{array}{l}\text { Slightly extended temperature-controlling period } \\
\text { during summer }\end{array}$ & 2 \\
\hline 2 & 1 & Spawning occurs in fully controlled environment & 1 & Level of impact unknown & 1 \\
\hline 3 & 1 & $\begin{array}{l}\text { Larval rearing occurs in fully controlled environ- } \\
\text { ment }\end{array}$ & 2 & $\begin{array}{l}\text { Strong negative impacts of seawater acidification } \\
\text { on larval development }\end{array}$ & 2 \\
\hline 4 & 2 & $\begin{array}{l}\text { Juvenile rearing occurs in a partially controlled } \\
\text { environment }\end{array}$ & 2 & $\begin{array}{l}\text { Strong negative impacts of increased intensity } \\
\text { and duration of high temperature }\end{array}$ & 4 \\
\hline 5 & 2 & $\begin{array}{l}\text { Growout occurs in partially controlled environ- } \\
\text { ment }\end{array}$ & 2 & $\begin{array}{l}\text { Strong negative impacts of increased intensity } \\
\text { and duration of high temperature }\end{array}$ & 4 \\
\hline 6 & 2 & $\begin{array}{l}\text { Some potential to move to alternative sites or } \\
\text { use alternative farming systems }\end{array}$ & 1 & Level of impact unknown & 2 \\
\hline 7 & 1 & $\begin{array}{l}\text { Manufactured feeds used } \\
\text { feeding practices }\end{array}$ & 1 & Mild impacts on feed storage, transportation and & 1 \\
\hline 8 & 1 & $\begin{array}{l}\text { Full farm cycle and infrastructure are onshore } \\
\text { and readily accessible }\end{array}$ & 0 & $\begin{array}{l}\text { Limited impacts on farming facilities and their } \\
\text { accessibilities }\end{array}$ & 0 \\
\hline \multirow[t]{2}{*}{9} & 3 & $\begin{array}{l}\text { temperature-related disease impacts are already } \\
\text { occurring in summer on many farms }\end{array}$ & 2 & $\begin{array}{l}\text { Increased intensity and duration of disease } \\
\text { impacts }\end{array}$ & 6 \\
\hline & & & \multicolumn{3}{|c|}{ Total risk score 22} \\
\hline
\end{tabular}

more distant. Increases in the severity, duration and frequency of extreme climatic events and sea level rise were also predicted to impact farm infrastructure, the suitability of current farming locations and day-to-day farming operations.

Regardless of the diverse array of farming systems represented, key data gaps and areas of uncertainty relevant to climate change impacts were strikingly similar between species (Table 5). Key data gaps identified included an understanding of climate change impacts on the species' physiology and immunology, impacts of climate change on interactions with harmful species that may affect performance and survival (e.g. pest, fouling and pathogenic species), ability of selective breeding to counteract the impacts of climate change and the limited availability of fine-scale oceanographic monitoring and model projections relevant to the locations of aquaculture operations. Impacts of ocean acidification were also highlighted as a key data gap for finfish species and abalone.

\section{Scoring assessment}

There was good resolution among the scoring assessments of the 11 industries, with total risk scores ranging from 9 to 34 . The scores indicated that the edible oyster industry in south-eastern Australia is at highest potential risk as a result of climate change (Fig. 2). This is primarily due to observed increases in summer temperatures and heatwave-related mortalities that are already emerging as an issue in both SA and NSW. Strong and moderate negative impacts were scored for both oyster species for most of the other attributes. Sydney rock oyster (SRO) farmed from wild spatfall (which is currently a much more common source than hatchery-produced spat) was the most sensitive of the oyster group, with an overall score of 34. Hatchery-produced SRO and Pacific oyster (PO) had similar high scores of 25 and 27, respectively.

Blue mussel, farmed from wild-caught spat, was the industry's second-most at risk (equalling PO) and ranked substantially higher risk than the hatcheryproduced mussels, with scores of 27 and 15, respectively. Strong climate change impacts are associated with early life-history stages (attributes 2 to 4 ) in mussels (wild), with natural spatfall already showing signs of decline in Victoria and SA. It is thought that the declines are related to drought in Victoria and atypical weather conditions and drought in SA, all affecting the productivity of microalgae, which is the main larval food source. However, the mussel 
Table 4. Summary of current and predicted climate change impacts outlined in detailed species profiles (see Pecl et al. 2011), with level of certainty of the associated information. Level of certainty is divided into: high (H): strong clear evidence, backed by several studies with solid datasets with little confounding interactions; medium (M): evidence supported by 1 or more studies, conclusions may be partially ambiguous or confounded; low (L): anecdotal evidence, limited data and/or predicted conclusions based on theoretical knowledge; ${ }^{*}$ : a current climate change impact, or current impacts which may be linked to climate change

Current and predicted biological impacts

Current and predicted operational impacts

\section{Abalone Haliotis spp.}

- 'Summer mortality', which is linked to reproductive stress, elevated temperatures, poor water quality, and disease, is common on farms which experience high summer temperatures (Vandepeer 2006) (M)*

- Increased severity and duration of 'summer mortality' (M)

- Ocean acidification may lead to increased larval and spat mortality, decreases in growth and abnormal shell development, especially on sea-based farms (Harris et al. 1999, Gazeau et al. 2007) (L)

- Increases in storms may lead to reduced growth at sea-based farms (Oulton 2009) (M)

\section{Atlantic salmon Salmo salar}

- Increases in temperature are likely to impact broodstock conditioning and egg quality (Pankhurst \& King 2010) (M)

- High summer temperatures and reduced rainfall in Tasmania already affect productivity and health, and cause an increase in disease outbreaks, particularly amoebic gill disease $(\mathrm{M})^{* a}$

- Further increases in diseases due to increased stress and immunesuppression (M) and reduced efficacy of vaccines $(\mathrm{L})^{\mathrm{a}}$

- Increase in harmful microalgae* and jellyfish $(\mathrm{M})^{\mathrm{a}}$

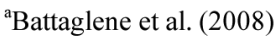

\section{Blue mussel Mytilus galloprovincialis}

- Decline in wild spatfall in Victoria has been linked to prolonged drought (Hutchinson et al. 2010) (L)*

- Increases in temperature may have negative impacts on growth, reproduction and health (Anestis et al. 2007, Ferreira et al. 2008, Fearman \& Moltschaniwskyj 2010) (M)

- Ocean acidification may lead to increased larval and spat mortality, decreases in growth and abnormal shell development (Gazeau et al. 2007, 2010) (M)

- Increases in disease (Anestis et al. 2010) (M)

Pacific oyster Crassostrea gigas

- Flatworm infestations, which can devastate oyster spat, have been linked to prolonged drought and high salinities (O'Connor \& Newman 2001) (M)*

- Ocean acidification may lead to increased larval and spat mortality, decreases in growth and abnormal shell development (Gazeau et al. 2007) (M)

- Increased severity of 'summer mortality', which is linked to temperature, salinity, $\mathrm{O}_{2}$ levels, reproductive stress and disease (Li et al. 2007, 2010) (M)

- Adults may spawn earlier in the year due to increased temperature (L)

\section{Southern bluefin tuna Thunnus maccoyii}

- Southward range shift of natural population (Hobday 2010)(L)

- Increases in upwelling in South Australia may lead to increases in prey/feed availability (small pelagics) (L)

- Increases in growth rates and production $(\mathrm{L})$

- Reduced $\mathrm{O}_{2}$ levels in sea cages due to elevated temperatures (L)

- Increases in parasites, disease and harmful microalgae (L)
- Increases in temperature may lead to increased water flow to landbased growout system $(\mathrm{H})$, greater use of shading of nursery and growout areas (M), increased use of cultured diatom species to seed settlement plates (L), increases in fouling organisms (L), refrigeration during live transport $(\mathrm{M})$, improved measures to store manufactured feed (M)

- Increases in flood events and fluctuating salinity levels and sea level rise (Oulton 2009) may affect farm site suitability in land-based systems (L)

- All hatcheries are expected to become temperature regulated $(\mathrm{H})^{\mathrm{a}}$

- Sea cages may be moved to further south or offshore to cooler waters $(\mathrm{L})^{\mathrm{a}}$

- Increased reliance on selective breeding programmes (M)

- Temperature increase may impact final product (i.e. poorer colour) $(\mathrm{L})^{\mathrm{a}}$

- Increases in harmful microalgae, which cause shellfish poisoning (Hallegraeff et al. 2009) (M)

- Increased reliance on hatchery production (L)

- Storm increases may lead to increased mechanical damage to infrastructure $(\mathrm{L})$

- Increased cleaning of infrastructure due to biofouling (L)

- More rigorous product transport, processing and packaging standards (L)

- Intertidal leases may become less suitable for farming due to sea level rise (M)

- Increases in harmful microalgae which cause shellfish poisoning (Hallegraeff et al. 2009) (M)

- Increased cleaning of infrastructure due to biofouling (L)

- More rigorous product transport, processing and packaging standards (L)

- Storm increases may lead to increased mechanical damage to infrastructure and reduce the time available for operational tasks (L)

- Temperature increase may impact final product (L)

- Increased cleaning of infrastructure due to biofouling (L)

- More rigorous product transport, processing and packaging standards (L)

- $\quad$ Reduced fallowing periods (L) 
Table 4 (continued)

\section{Sydney rock oyster Saccostrea glomerata}

- Decline in fertilisation success due to changes in $\mathrm{pH}$ and temperature (Parker et al. 2009, 2010) (H)

- Ocean acidification may lead to increased larval and spat mortality, decreases in growth and abnormal shell development (Watson et al. 2009) (M)

- Increase in 'winter mortality' and QX disease due to increased stress $(\mathrm{M})$

\section{Yellowtail kingfish Seriola lalandi}

- Gill and skin flukes present greater problems in increased water temperatures (Mooney et al. 2006) $(\mathrm{H})^{*}$

- Increases in parasitic infections, microalgal and jellyfish blooms (M)

- Elevated temperatures may lead to increased growth (Poortenaar et al. 2003) (H), but this may be offset by increases in salinity which may reduce growth (Oulton 2009) (M)
- Intertidal leases may become less suitable for farming due to sea level rise $(\mathrm{H})$

- Increased cleaning of infrastructure due to biofouling (L)

- Increased costs associated with the quality assurance programme (L)

- More rigorous product transport, processing and packaging standards (L)

- Increased use of parasite control measures (i.e. bathing) (H)

- Reduced working time on offshore cages (L)

- Reduced fallowing periods (L)

- Increases in net replacements due to increased biofouling (L)

- New harvesting strategies (to avoid 'burnt muscle' at high temperatures (Arroyo Mora et al. 2007) (L)

- More rigorous product transport, processing and packaging standards $(\mathrm{L})$ growout stage, which is the same for both spat production methods, is less sensitive than that of other shellfish species farmed in intertidal regions. Mussels are less prone to rapid environmental change or extreme variability as they are farmed in deeper subtidal, wave-protected regions, where temperature extremes are less likely. Overall, for the shellfish species, comparisons between hatchery and wild produced spat strongly indicate reduced risk with increased environmental control of the production cycle.

Abalone was ranked at moderate risk, with landbased growout systems rated the most vulnerable to climate change impacts. Sensitivity scores were relatively low for land-based farming, which is largely due to the level of environmental control which can be applied throughout the lifecycle. However, impact scores were generally rated as strong to moderate due to the existing temperature and disease impacts experienced in summer on many land-based farms in SA and Victoria.

The finfish species, on average, were ranked as being at low risk compared to the shellfish species. Southern bluefin tuna (SBT) was assessed as relatively resilient, for both sea-ranching and hatchery production methods. SBT may be impacted by climate change both positively (e.g. increases in growth rate) and negatively (e.g. increases in the occurrence of harmful algal blooms); however, there is also great uncertainty with regard to potential impacts. Yellowtail kingfish (YTK) had the lowest total risk score (9), which was lower than the total sensitivity score (16)

Table 5. Summary of data gaps (*) as collated from individual species profiles (Stage 1 of the risk assessment). Ab: abalone; PO: Pacific oyster; AS = Atlantic salmon; SBT: southern bluefin tuna; YTK: yellowtail kingfish; BM: blue mussel; SRO: Sydney rock oyster

\begin{tabular}{|c|c|c|c|c|c|c|c|}
\hline Data gap & $\mathrm{Ab}$ & $\mathrm{PO}$ & AS & SBT & YTK & $\mathrm{BM}$ & SRO \\
\hline $\begin{array}{l}\text { Ability of selective breeding and/or genetic variation to counteract impacts of } \\
\text { climate change }\end{array}$ & * & * & & * & * & * & * \\
\hline Fine-scale climate change modelling and monitoring relevant to aquaculture farms & * & * & * & * & * & & * \\
\hline $\begin{array}{l}\text { Impacts of climate change on inter-specific interactions which may affect } \\
\text { performance and survival (e.g. pest, fouling and pathogenic species) }\end{array}$ & * & * & * & * & * & * & \\
\hline Impacts of climate change on the species' physiology and immunology & * & * & * & * & * & & \\
\hline Impacts of ocean acidification & * & & * & * & * & & \\
\hline Precise cause of summer mortality & * & * & & & & & \\
\hline Effect of elevated temperature on vaccine efficacy & & & * & & & & \\
\hline General biology and impacts of climate change on wild populations & & & & & & * & \\
\hline
\end{tabular}




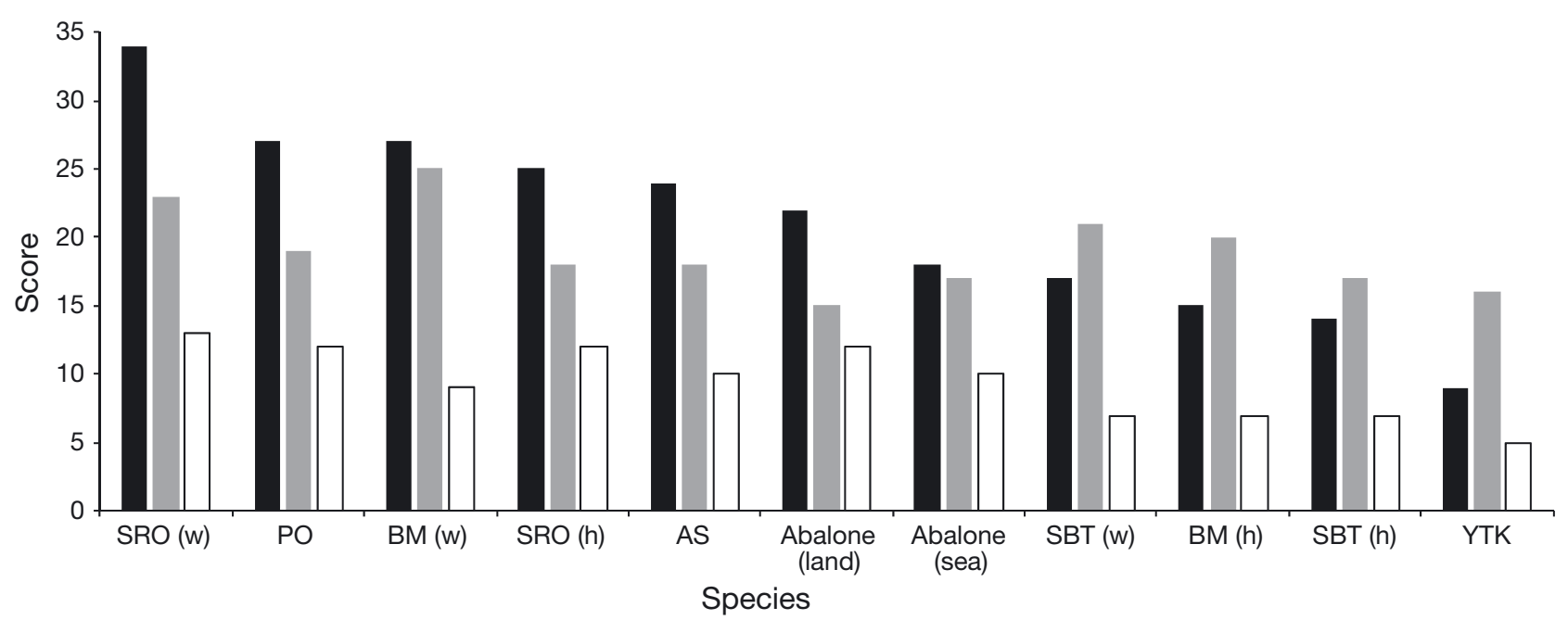

Fig. 2. Total risk scores for each species and farming system (black columns), ordered from high risk to low risk. Total sensitivity (grey columns) and total impact scores (white columns) are also displayed. Data chart of all scores is presented in Appendix 1. SRO: Sydney rock oyster; PO: Pacific oyster; BM: blue mussel; AS: Atlantic salmon; SBT: southern bluefin tuna; YTK: yellowtail kingfish; w: juveniles or spat sourced from the wild; h: spat produced in hatcheries

for this species. This is because climate change impacts were only considered to be moderate, mild, or positive as environmental conditions are well controlled in hatcheries and temperature increases are expected to increase growth rates and productivity during the growout stage. Atlantic salmon received a moderately high sensitivity score and moderate to strong impact score. Higher levels of risk were primarily related to the growout stage, with increases in disease and the lack of future suitable cold water farm locations being key concerns.

The total risk scores for each attribute, across all species, showed that the level of connectivity of growout to the natural environment (Attribute 5) and disease and pest management (Attribute 9) greatly influenced the level of risk (Fig. 3). Larval rearing (Attribute 3 ) had a moderately high total risk score, which was primarily associated with the shellfishrelated risk assessments of species reliant on natural spatfall, with most scoring an impact score of 2 (strong anticipated climate change impact). The availability of alternative farm sites and systems (Attribute 6) had the lowest score, with salmon being the only species receiving an impact score of 2 . All other attributes showed moderate levels of relative risk.

\section{DISCUSSION}

The qualitative risk assessment presented here involved a simple and repeatable methodology, which was appropriate for a divergent range of aquaculture systems and taxa, and should be applicable to other regions around the world. Additionally, the method

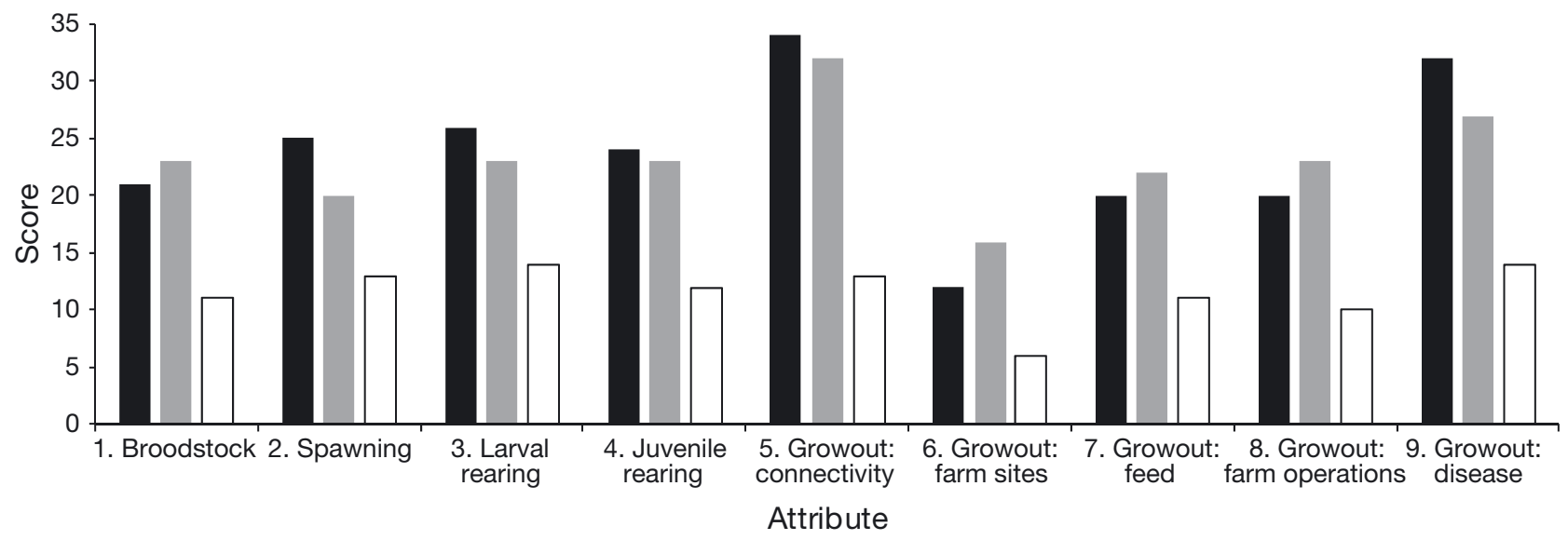

Fig. 3. Total attribute risk scores for each attribute (black columns). Total sensitivity (grey columns) and total impact scores (white columns) are also displayed 
allowed relatively severe impacts to have greater influence over the scores (e.g. such as the relative inability of salmon farms to shift further south to avoid increasing water temperatures), and for uncertainty and positive impacts to be incorporated into the analysis, which produced a more realistic classification of relative risk among species and farming systems. In general, there was qualitative agreement between the conclusions drawn from the species profiles and total risk scores, with each of the 2 components providing complementary information. The species profiles provided the necessary information to develop the attributes and scoring level for each species, and the risk scores provided a framework in which to compare a large and complex range of associated risks among species. For instance, it would be difficult to rank species according to level of predicted impacts based on the information given in the profiles alone (see Tables $4 \& 5$ for summaries). In light of this, however, the scoring assessment should not be treated as the end-product of the results, but interpreted in combination with descriptive information. For example, the profiles additionally highlighted key climate change drivers such as temperature, $\mathrm{pH}$, extreme climatic events and sea level rise, current and anticipated impacts, regional variability in production and the physical environment, and, importantly, the level of uncertainty with regard to anticipated impacts. Generating descriptive information can also involve a range of stakeholders, which is an important prerequisite in undertaking risk assessments (Hobday et al. 2011). The 2 components of the risk assessment also provided complementary information on 2 intrinsically linked concepts: what can be done to ameliorate climate change impacts versus what is the impact of the adaptation strategy itself. The species profiles generally described sensitivity of biological or operational systems to climate signals and the scoring assessment focused on the adaptive capacity of the farming process including its capacity to control environmental conditions.

This study developed a screening-level assessment, which is seen as a valuable approach to guide the selection and prioritization of future research and development of cost-effective solutions (Scandol et al. 2009, Hobday et al. 2011, Waugh et al. 2012). The results from this risk assessment have been presented at several conferences, workshops, and industry and management forums and are already guiding the development of strategic research plans with several of the industry groups in south-east Australia. Although the method presented could be easily modified to differentiate risk at finer spatial scales, the broad scope of this assessment limited consideration of the degree to which aquaculture farms throughout the entire south-east region would be impacted by regional variations in exposure to climate change variables. It would be necessary in future assessments on high and medium risk species (and especially those that are farmed throughout the southeast) to include intra-regional and species-specific levels of exposure to key climate change drivers (see Leith \& Haward 2010). However, as highlighted in the species profiles, a key data gap for aquaculture is the limited information on climate change at subregional or local scales (see Table 5). It would be useful, therefore, that such data gaps are addressed so that more detailed risk assessments can be developed. While beyond the scope of this study, which focused on biophysical risk, future first-pass assessments could also include social and economic risk, which could be informed by considering a supplychain business analysis for each product (e.g. Oulton 2009). This will be important for future assessments as we need to interpret risk results in the broader context of the social-ecological system, in which ability to cope with effects of climate change will depend on sensitivities and adaptive capacities of the linked human system (Moser \& Ekstrom 2010, Marshall et al. in press).

This screening-level risk assessment provides guidance to scientists, resource managers and stakeholders on how climate change is expected to alter the physiology, life cycles and environment of aquaculture species and, ultimately, the way they are farmed. The study also highlights critical data gaps in aquaculture research across a broad range of farming systems. Outcomes from this assessment will focus attention towards the research required to underpin more detailed quantitative assessments of higher risk industries within the region and thus more optimal allocation of human and operational resources. Aquaculture production provides significant social and economic benefits globally, and the methods presented provide a broadly applicable, cost-effective and rapid approach to assessing risk and prioritising research, and should be relevant to many other regions around the world.

Acknowledgements. We thank the following people for their expert contributions towards compiling the species profiles, including: Pheroze Jungawalla (formally Tasmanian Salmonid Growers Association), Barbara Nowak (University of Tasmania), Natalie Moltschaniwsky (University of Newcastle), Nick Savva (Abtas Marketing), Gary Zippel (Zippel Enterprises), Wayne O'Connor (Port Stephens Fisheries Institute), David Ellis (Australian Southern Bluefin Tuna 
Aquaculture Industry Association), Mark Gluis, David Stone and Bennan Chen (South Australian Research \& Development Institute [SARDI]). Numerous other people also supplied various images for use in the species profiles. We also thank Daniel Spooner (formerly Department of Primary Industries [DPI], Victoria) for his input at the workshops. This project (FRDC No. 2009/070) was funded by the El Nemo South East Australia Program (SEAP) which is a partnership between Australia's State and Commonwealth fisheries management and research agencies including, Australian Fisheries Management Authority, CSIRO, DPI (Victoria), Fisheries Research \& Development Corporation, Industry \& Investment NSW, SARDI, Department of Primary Industries, Parks, Water \& Environment (Tasmania) and the University of Tasmania. SEAP is co-funded through the Australian Government's Climate Change Research Programa key component of the Commonwealth Government's Australia's Farming Future initiative.

\section{LITERATURE CITED}

ABARE (Australian Bureau of Agricultural and Resource Economics and Fisheries Research and Development Corporation) (2011) Australian fisheries statistics 2010. ABARE, Canberra

Allison EH, Perry AL, Badjeck MC, Neil Adger W and others (2009) Vulnerability of national economies to the impacts of climate change on fisheries. Fish Fish 10:173-196

Anestis A, Lazou A, Portner HO, Michaelidis B (2007) Behavioral, metabolic, and molecular stress responses of marine bivalve Mytilus galloprovincialis during longterm acclimation at increasing ambient temperature. Am J Physiol Regul Integr Comp Physiol 293:R911-R921

Anestis A, Pörtner HO, Karagiannis D, Angelidis P, Staikou A, Michaelidis B (2010) Response of Mytilus galloprovincialis (L.) to increasing seawater temperature and to marteliosis: metabolic and physiological parameters. Comp Biochem Physiol A Mol Integr Physiol 156:57-66

Arrizabalaga H, de Bruyn P, Diaz GA, Murua H and others (2011) Productivity and susceptibility analysis for species caught in Atlantic tuna fisheries. Aquat Living Resour $24: 1-12$

Arroyo Mora D, Hamada Y, Okamoto A, Tateishi A, Tachibana K (2007) Characteristics of burnt meat in cultured yellowtail Seriola quinqueradiata. Fish Sci 73: 651-659

AS/NZS (Standards Australia and Standards New Zealand) (2009) ISO 31000. Risk management-principles and guidelines. Standards Australia and Standards New Zealand, Sydney

Battaglene S, Carter C, Hobday A, Lyne V, Nowak B (2008) Scoping study into adaptation of the Tasmanian salmonid aquaculture industry to potential impacts of climate change. National Agriculture and Climate Change Action Plan: Implementation Programme, Tasmanian Aquaculture and Fisheries Institute, University of Tasmania, and CSIRO Marine and Atmospheric Research, Hobart

Bostock J, McAndrew B, Richards R, Jauncey K and others (2010) Aquaculture: global status and trends. Philos Trans R Soc Lond B Biol Sci 365:2897-2912

Brander KM (2007) Global fish production and climate change. Proc Natl Acad Sci USA 104:19709-19714

Brierley AS, Kingsford MJ (2009) Impacts of climate change on marine organisms and ecosystems. Curr Biol 19: R602-R614

Chin A, Kyne PM, Walker TI, McAuley R (2010) An integrated risk assessment for climate change: analysing the vulnerability of sharks and rays on Australia's Great Barrier Reef. Glob Change Biol 16:1936-1953

Cochrane K, De Young C, Soto D, Bahri T (eds) (2009) Climate change implications for fisheries and aquaculture: overview of current scientific knowledge. FAO Fisheries and Aquaculture Technical Paper, No. 530. Food and Agricultural Organisation of the United Nations, Rome

De Silva SS (2012) Climate change impacts: challenges for aquaculture. In: Subasinghe RP, Arthur JR, Bartley DM, De Silva SS and others (eds) Farming the waters for people and food. Proceedings of the Global Conference on Aquaculture 2010. FAO, Rome and NACA, Bangkok, p 75-110

De Silva SS, Soto D (2009) Climate change and aquaculture: potential impacts, adaptation and mitigation. In: Cochrane K, De Young C, Soto D, Bahri T (eds) Climate change implications for fisheries and aquaculture: overview of current scientific knowledge. FAO Fisheries and Aquaculture Technical Paper, No. 530. FAO, Rome, p 151-212

Econsearch (2011) The economic impact of aquaculture on the South Australian state and regional economies, 2009/10. A report prepared for PIRSA Fisheries and Aquaculture, Adelaide

> Fearman J, Moltschaniwskyj NA (2010) Warmer temperatures reduce rates of gametogenesis in temperate mussels, Mytilus galloprovincialis. Aquaculture 305:20-25

Ferreira JG, Hawkins AJS, Monteiro P, Moore H and others (2008) Integrated assessment of ecosystem-scale carrying capacity in shellfish growing areas. Aquaculture 275:138-151

Fletcher WJ (2005) The application of qualitative risk assessment methodology to prioritize issues for fisheries management. ICES J Mar Sci 62:1576-1587

Gallagher AJ, Kyne PM, Hammerschlag N (2012) Ecological risk assessment and its application to elasmobranch conservation and management. J Fish Biol 80:1727-1748

Garcia SM, Rosenberg AA (2010) Food security and marine capture fisheries: characteristics, trends, drivers and future perspectives. Philos Trans R Soc Lond B Biol Sci 365:2869-2880

Gazeau F, Quiblier C, Jansen JM, Gattuso J, Middelburg JJ, Heip CHR (2007) Impact of elevated $\mathrm{CO}_{2}$ on shellfish calcification. Geophys Res Lett 34:L07603, doi:10.1029/2006 GL028554

Gazeau F, Gattuso JP, Dawber C, Pronker AE and others (2010) Effect of ocean acidification on the early life stages of the blue mussel Mytilus edulis. Biogeosciences 7:2051-2060

Gillanders BM, Elsdon TS, Halliday IA, Jenkins GP, Robins JB, Valesini FJ (2011) Potential effects of climate change on Australian estuaries and fish utilising estuaries: a review. Mar Freshw Res 62:1115-1131

> Godfray HCJ, Beddington JR, Crute IR, Haddad L and others (2010) Food security: the challenge of feeding 9 billion people. Science 327:812-818

Hallegraeff G, Beardall J, Brett S, Doblin M, Hosja W, de Salas M, Thompson P (2009) Phytoplankton. In: Poloczanska ES, Hobday AJ, Richardson AJ (eds) A marine climate change impacts and adaptation report card for Australia. Publication 05/09, NCCARF, Southport 
Handisyde NT, Ross LG, Badjeck MC, Allison EH (2006) The effects of climate change on world aquaculture: a global perspective. Final technical report, Department for International Development, Stirling Institute of Aquaculture, Stirling

Harris JO, Maguire GB, Edwards SJ, Hindrum SM (1999) Effect of $\mathrm{pH}$ on growth rate, oxygen consumption rate, and histopathology of gill and kidney tissue for juvenile greenlip abalone, Haliotis laevigata Donovan and blacklip abalone, Haliotis rubra Leach. J Shellfish Res 18:611-619

Hill KL, Rintoul SR, Coleman R, Ridgway KR (2008) Wind forced low frequency variability of the East Australia Current. Geophys Res Lett 35:L08602, doi:10.1029/2007 GL032912

Hobday A (2010) Ensemble analysis of the future distribution of large pelagic fishes off Australia. Prog Oceanogr 86:291-301

Hobday AJ, Lough JM (2011) Projected climate change in Australian marine and freshwater environments. Mar Freshw Res 62:1000-1014

Hobday AJ, Poloczanska ES, Matear R (eds) (2008) Implications of climate change for Australian fisheries and aquaculture: a preliminary assessment. Report to the Department of Climate Change, Canberra

Hobday AJ, Smith ADM, Stobutzki IC, Bulman C and others (2011) Ecological risk assessment for the effects of fishing. Fish Res 108:372-384

Hutchinson N, Gavine F, Morris E, Longmore A (2010) Adaptation of fisheries and fisheries management to climate change: marine, estuarine and freshwater biophysical risk assessment. Fisheries Victoria Technical Report No. 92, Department of Primary Industries, Queenscliff

IPCC (Intergovernmental Panel on Climate Change) (2007) Summary for policymakers. In: Solomon S, Qin D, Manning M, Chen Z and others (eds) Climate change 2007: the physical science basis. Contribution of Working Group I to the 4th Assessment Report of the IPCC. Cambridge University Press, Cambridge

Leith PB, Haward M (2010) Climate change adaptation in the Australian edible oyster industry: an analysis of policy and practice. University of Tasmania, Hobart

Li Y, Qin JG, Abbott CA, Li X, Benkendorff K (2007) Synergistic impacts of heat shock and spawning on the physiology and immune health of Crassostrea gigas: an explanation for summer mortality in Pacific oysters. Am J Physiol 293:2353-2362

Li Y, Qin JG, Li X, Benkendorff K (2010) Assessment of metabolic and immune changes in postspawning Pacific oyster Crassostrea gigas: identification of a critical period of vulnerability after spawning. Aquacult Res 41: e155-e165

Marshall NA, Tobin RC, Gooch M, Hobday AJ, Marshall PA (in press) Vulnerability of marine resource users to extreme weather events. Ecosystems

> Mooney AJ, Ernst I, Whittington ID (2006) An egg-laying rhythm in Zeuxapta seriolae (Monogenea: Heteraxinidae), a gill parasite of yellowtail kingfish (Seriola lalandi). Aquaculture 253:10-16

Moser SC, Ekstrom JA (2010) A framework to diagnose barriers to climate change adaptation. Proc Natl Acad Sci USA 107:22026-22031
O'Connor WA, Newman LJ (2001) Halotolerance of the oyster predator, Imogine mcgrathi, a stylochid flatworm from Port Stephens, New South Wales, Australia. Hydrobiologia 459:157-163

Oulton LJ (2009) Assessing the impact of anthropogenic climate change on the aquaculture industry in South Australia: abalone as a case example. Masters thesis, University of London, London

Pankhurst NW, King HR (2010) Temperature and salmonid reproduction: implications for aquaculture. J Fish Biol 76: 69-85

> Parker LM, Ross PM, O'Connor WA (2009) The effect of ocean acidification and temperature on the fertilization and embryonic development of the Sydney rock oyster Saccostrea glomerata (Gould, 1850). Glob Change Biol 15:2123-2136

> Parker LM, Ross PM, O'Connor WA (2010) Comparing the effect of elevated $\mathrm{pCO}_{2}$ and temperature on the fertilization and early development of two species of oysters. Mar Biol 157:2435-2452

Pecl GT, Doubleday Z, Ward T, Clarke S and others (2011) Risk assessment of impacts of climate change for key marine species in South Eastern Australia. Fisheries Research and Development Corporation, Project No. 2009/070. Available at www.imas.utas.edu.au/_data/ assets/pdf_file/0017/222092/Risk-assessment-report_Part2Species-profiles-02.pdf

Poloczanska ES, Babcock RC, Butler A, Hobday AJ and others (2007) Climate change and Australian marine life. Oceanogr Mar Biol Annu Rev 45:407-478

Poortenaar C, Jeffs A, Heath P, Hooker S (2003) Commercial opportunities for kingfish aquaculture in northland. NIWA, Auckland

Ridgway KR (2007) Long-term trend and decadal variability of the southward penetration of the East Australian Current. Geophys Res Lett 34:L13612, doi:10.1029/2007GL 030393

> Samhouri JF, Levin PS (2012) Linking land- and sea-based activities to risk in coastal ecosystems. Biol Conserv 145: 118-129

Scandol J, Ives M, Lockett M (2009) Development of national guidelines to improve the application of riskbased methods in the scope, implementation and interpretation of stock assessments for data-poor species. FRDC Project No. 2007/016, Industry \& Investment NSW, Cronulla

Solomon S, Plattner GK, Knutti R, Friedlingstein P (2009) Irreversible climate change due to carbon dioxide emissions. Proc Natl Acad Sci USA 106:1704-1709

Vandepeer M (2006) Preventing summer mortality of abalone in aquaculture systems by understanding interactions between nutrition and water temperature. FRDC final report, SARDI Aquatic Sciences, Adelaide

Watson SA, Southgate PC, Tyler PA, Peck LS (2009) Early larval development of the Sydney rock oyster Saccostrea glomerata under near-future predictions of $\mathrm{CO}_{2}$ driven ocean acidification. J Shellfish Res 28:431-437

> Waugh SM, Filippi DP, Kirby DS, Abraham E, Walker N (2012) Ecological risk assessment for seabird interactions in western and central Pacific longline fisheries. Mar Policy 36:933-946 


\section{Appendix 1.}

Table A1. Complete scoring for each of the 11 risk assessments. SS: sensitivity score; IS: impact score; RS: risk score. The RS for each attribute is the SS multiplied by the IS. AS: Atlantic salmon; BM: blue mussel; PO: Pacific oyster; SRO: Sydney rock oyster; SBT: southern bluefin tuna; YTK: yellowtail kingfish; w: juveniles or spat sourced from the wild; h: spat produced in hatcheries

\begin{tabular}{|c|c|c|c|c|c|c|c|c|c|c|c|c|}
\hline \multirow[t]{2}{*}{ Attribute } & \multicolumn{3}{|c|}{ Abalone (land) } & \multicolumn{3}{|c|}{ Abalone (sea) } & \multicolumn{3}{|c|}{ AS } & \multicolumn{3}{|c|}{$\mathrm{BM}(\mathrm{h})$} \\
\hline & SS & IS & $\mathrm{RS}$ & SS & IS & RS & SS & IS & RS & SS & IS & $\mathrm{RS}$ \\
\hline 1 & 2 & 1 & 2 & 2 & 1 & 2 & 1 & 1 & 1 & 2 & 1 & 2 \\
\hline 2 & 1 & 1 & 1 & 1 & 1 & 1 & 2 & 1 & 2 & 1 & 1 & 1 \\
\hline 3 & 1 & 2 & 2 & 1 & 2 & 2 & 2 & 0 & 0 & 2 & 2 & 4 \\
\hline 4 & 2 & 2 & 4 & 2 & 2 & 4 & 1 & 0 & 0 & 2 & 1 & 2 \\
\hline 5 & 2 & 2 & 4 & 3 & 1 & 3 & 3 & 2 & 6 & 3 & 0 & 0 \\
\hline 6 & 2 & 1 & 2 & 2 & 0 & 0 & 3 & 2 & 6 & 1 & 0 & 0 \\
\hline 7 & 1 & 1 & 1 & 2 & 1 & 2 & 1 & 1 & 1 & 3 & 1 & 3 \\
\hline 8 & 1 & 0 & 0 & 2 & 1 & 2 & 2 & 1 & 2 & 3 & 1 & 3 \\
\hline 9 & 3 & 2 & 6 & 2 & 1 & 2 & 3 & 2 & 6 & 3 & 0 & 0 \\
\hline Total & 15 & 12 & 22 & 17 & 10 & 18 & 18 & 10 & 24 & 20 & 7 & 15 \\
\hline \multirow[t]{2}{*}{ Attribute } & \multicolumn{3}{|c|}{$\mathrm{BM}(\mathrm{w})$} & \multicolumn{3}{|c|}{$\mathrm{PO}$} & \multicolumn{3}{|c|}{ SRO (h) } & \multicolumn{3}{|c|}{ SRO $(w)$} \\
\hline & SS & IS & RS & SS & IS & $\mathrm{RS}$ & SS & IS & RS & SS & IS & RS \\
\hline 1 & 3 & 1 & 3 & 1 & 1 & 1 & 2 & 1 & 2 & 3 & 1 & 3 \\
\hline 2 & 3 & 2 & 6 & 1 & 1 & 1 & 1 & 1 & 1 & 3 & 2 & 6 \\
\hline 3 & 3 & 2 & 6 & 2 & 2 & 4 & 2 & 2 & 4 & 3 & 2 & 6 \\
\hline 4 & 3 & 2 & 6 & 2 & 1 & 2 & 2 & 1 & 2 & 3 & 1 & 3 \\
\hline 5 & 3 & 0 & 0 & 3 & 2 & 6 & 3 & 2 & 6 & 3 & 2 & 6 \\
\hline 6 & 1 & 0 & 0 & 2 & 1 & 2 & 1 & 1 & 1 & 1 & 1 & 1 \\
\hline 7 & 3 & 1 & 3 & 3 & 1 & 3 & 3 & 1 & 3 & 3 & 1 & 3 \\
\hline 8 & 3 & 1 & 3 & 2 & 1 & 2 & 2 & 1 & 2 & 2 & 1 & 2 \\
\hline 9 & 3 & 0 & 0 & 3 & 2 & 6 & 2 & 2 & 4 & 2 & 2 & 4 \\
\hline Total & 25 & 9 & 27 & 19 & 12 & 27 & 18 & 12 & 25 & 23 & 13 & 34 \\
\hline \multirow[t]{2}{*}{ Attribute } & \multicolumn{3}{|c|}{ SBT (h) } & \multicolumn{3}{|c|}{ SBT (w) } & \multicolumn{3}{|c|}{ YTK } & & & \\
\hline & SS & IS & RS & SS & IS & $\mathrm{RS}$ & SS & IS & RS & & & \\
\hline 1 & 2 & 1 & 2 & 3 & 1 & 3 & 2 & 1 & 2 & & & \\
\hline 2 & 2 & 1 & 2 & 3 & 1 & 3 & 2 & 1 & 2 & & & \\
\hline 3 & 2 & 0 & 0 & 3 & 0 & 0 & 2 & 0 & 0 & & & \\
\hline 4 & 2 & 1 & 2 & 3 & 1 & 3 & 1 & 0 & 0 & & & \\
\hline 5 & 3 & 1 & 3 & 3 & 1 & 3 & 3 & 0 & 0 & & & \\
\hline 6 & 1 & 0 & 0 & 1 & 0 & 0 & 1 & 0 & 0 & & & \\
\hline 7 & 1 & 1 & 1 & 1 & 1 & 1 & 1 & 1 & 1 & & & \\
\hline 8 & 2 & 1 & 2 & 2 & 1 & 2 & 2 & 1 & 2 & & & \\
\hline 9 & 2 & 1 & 2 & 2 & 1 & 2 & 2 & 1 & 2 & & & \\
\hline Total & 17 & 7 & 14 & 21 & 7 & 17 & 16 & 5 & 9 & & & \\
\hline
\end{tabular}

Editorial responsibility: Megan La Peyre, Baton Rouge, Louisiana, USA
Submitted: October 5, 2012; Accepted: January 18, 2013 Proofs received from author(s): March 8, 2013 